\title{
Controle e prevenção das hepatites B e C na gravidez segundo profissionais da saúde
}

\author{
Hepatitis B and C control and prevention in pregnancy according to health professionals \\ Control y prevención de las hepatitis B y C en el embarazo según los profesionales de la salud
}

Recebido: 25/01/2022 | Revisado: 30/01/2022 | Aceito: 06/02/2022 | Publicado: 12/02/2022

\author{
Pilar Maria de Oliveira Moraes \\ ORCID: https://orcid.org/0000-0003-2817-4574 \\ Fundação Santa Casa de Misericórdia do Pará, Brasil \\ E-mail:pilarmoraesnutri@gmail.com \\ Elisabeth Christine Dias Ribeiro \\ ORCID: https://orcid.org/0000-0001-5551-0671 \\ Instituto Evandro Chagas, Brasil \\ E-mail: ellisa.cris@hotmail.com \\ Vanda Heloiza Marvão Soares \\ ORCID: https://orcid.org/0000-0002-46603-7920 \\ Fundação Santa Casa de Misericórdia do Pará, Brasil \\ Fundação Oswaldo Cruz, Brasil \\ E-mail: helomarvao@gmail.com \\ Ingrid Magali de Souza Pimentel \\ ORCID: https://orcid.org/0000-0003-1820-5496 \\ Universidade do Estado do Pará, Brasil \\ E-mail:imbarleta@yahoo.com.br \\ Thaís de Oliveira Carvalho Granado Santos \\ ORCID: https://orcid.org/0000-0001-9496-4561 \\ Fundação Santa Casa de Misericórdia do Pará, Brasil \\ E-mail: thaisgranadosantos@gmail.com \\ Xaene Maria Fernandes Duarte Mendonça \\ ORCID: https://orcid.org/0000-0002-0958-276X \\ Fundação Santa Casa de Misericórdia do Pará, Brasil \\ E-mail: xaenemaria@ufpa.gov.br \\ Lizomar de Jesus Maués Pereira Móia \\ ORCID: https://orcid.org/0000-0002-6755-8725 \\ Universidade do Estado do Pará, Brasil \\ E-mail: 1izmoia@yahoo.com.br \\ Juarez Antônio Simões Quaresma \\ ORCID: https://orcid.org/0000-0002-6267-9966 \\ Universidade do Estado do Pará, Brasil \\ E-mail: juarez.quaresma@gmail.com
}

\begin{abstract}
Resumo
Objetivo: Analisar a percepção de profissionais da saúde sobre os protocolos para controle e prevenção das Hepatites B e C: da gravidez à amamentação. Métodos: Trata-se de estudo transversal qualitativo, realizado em maternidade de referência no Pará e aprovado no comitê de ética sob parecer número: 2.037.289. A coleta de dados foi realizada em fevereiro de 2019 com profissionais e residentes multiprofissionais em saúde da linha do cuidado materno infantil, sendo aplicado questionário com quatro itens sobre o conhecimento dos procedimentos para controle e prevenção das hepatites B e C: da gravidez à amamentação. Resultados: O estudo abrangeu 20 profissionais, a maioria residentes $(52,2 \%)$, com $34 \%$ sugerindo que o hospital trabalhasse estratégias relacionadas à educação em saúde para comunidade e educação permanente, $3 \%$ desconheciam os protocolos do pré-natal e $13 \%$ os da sala de parto para prevenção da transmissão vertical. Em relação à amamentação, 16\% tinham dúvidas sobre a contraindicação de mães soropositivas para hepatites quanto ao manejo e indicação para amamentação segura. Conclusão: $\mathrm{O}$ uso de protocolos de prevenção e controle para hepatites virais ainda precisa ser mais difundido e aplicado, sendo o planejamento de estratégias de educação e saúde e educação permanente associados à sistema digital como meio mais indicado para o alcance de todos na contemporaneidade.
\end{abstract}

Palavras-chave: Amamentação; Hepatite B; Hepatite C; Gravidez. Prevenção.

\begin{abstract}
Objective: Analyze the perception of health professionals about the protocols for control and prevention of hepatitis B and C: from pregnancy to breastfeeding. Method: This is a qualitative cross-sectional study, carried out in a reference maternity hospital in Pará and approved by ethics committee under the registration 2.037.289. The data collection was carried out in February 2019 and had participation of professionals and multiprofessional health residents of the maternal and childcare line. A four-item questionnaire was applied on the knowledge of procedures for the control
\end{abstract}


and prevention of hepatitis B and C: from pregnancy to breastfeeding. Results: The study covered 23 participants, most of whom were multiprofessional residents $(52.2 \%)$, with $34.0 \%$ suggesting that the hospital worked on health and education strategies for the community and continuing education, $3 \%$ were unaware of prenatal protocols and $13 \%$ of the delivery room to prevent vertical transmission. Regarding breastfeeding, $16 \%$ had doubts about the contraindication of seropositive mothers for hepatitis regarding the indication and support for safe breastfeeding. Conclusion: The use of prevention and control protocols for viral hepatitis still needs to be more widespread and applied, with the planning of education and health and permanent education strategies associated with the digital system as the most suitable means for reaching everyone in a contemporary world.

Keywords: Breastfeeding; Hepatitis B; Hepatitis C; Pregnancy; Prevention.

\section{Resumen}

Objetivo: Analizar la percepción de los profesionales de la salud sobre los protocolos para el control y prevención de las Hepatitis B y C: del embarazo a la lactancia. Método: Se trata de un estudio transversal cualitativo realizado en una maternidad de referência en Pará y aprobado por el comité de ética con el parecer número: 2.037.289. La recolección de datos se realizó en febrero de 2019 con profesionales y residentes multiprofesionales de la salud en la línea de atención maternoinfantil, y se aplicó un cuestionario de cuatro ítems sobre el conocimiento de los procedimientos para el control y prevención de las hepatitis B y C: desde el embarazo a la lactancia materna. Resultados: Participaron en el estudio 20 profesionales, la mayoría residentes (52,2\%), siendo que el 34\% sugirieron que el hospital trabaja estrategias relacionadas con la educación en salud para la comunidad y la educación continua, el 3\% desconocía los protocolos de prenatal y el 13\% los del hospital. sala de partos para evitar la transmisión vertical. En cuanto a la lactancia materna, el 16\% tenía dudas sobre la contraindicación de las madres seropositivas para hepatitis en cuanto al manejo e indicación de la lactancia materna segura. Conclusión: El uso de protocolos de prevención y control de las hepatitis virales aún necesita ser más difundido y aplicado, con la planificación de estrategias de educación y salud y la educación continua asociada al sistema digital como el medio más adecuado para llegar a todos en la contemporaneidad.

Palabras clave: Lactancia materna; Hepatitis B; Hepatitis C; Embarazo; Prevención.

\section{Introdução}

Em 2016, a Organização Mundial da Saúde (OMS) consensuou que as hepatites virais deveriam ser eliminadas até 2030, porém poucos países têm plano de eliminação, faltando ferramentas com compromissos e monitoramento para o alcance desta meta (OMS, 2017; Brasil, 2021).

Desta forma, a adoção de controle e medidas de prevenção à transmissão pode alterar de muitas maneiras a experiência da gestação e da maternidade, onde puérperas infectadas possam minimizar os sentimentos de medo, tristeza, dor, angústia e culpa e risco de transmissão vertical de hepatites virais (Batista, 2007; Geraldo Duarte, 2021).

$\mathrm{O}$ uso dos testes rápidos (TR) para HBsAg e anti-HCV no pré-natal possibilitam a triagem e posterior confirmação com sorologias para Vírus da Hepatite B-VHB, bem como as medidas de profilaxia da transmissão vertical dos agravos, em função da rapidez do diagnóstico após triagem dos casos, devem ser realizadas na primeira consulta, independentemente da idade gestacional, com a garantia de resultados, em no máximo 15 dias, para os devidos encaminhamentos; na admissão para o parto e, em último caso, no puerpério (Brasil, 2021; 2010; Borgia, 2012) .

As hepatites que têm importância nas contraindicações temporárias da amamentação, são as B e C. Apesar do vírus da hepatite B ser encontrado no leite materno, com risco de transmissão de até $5 \%$, o aleitamento em crianças filhas de mães portadoras do vírus B está indicado logo após a aplicação da primeira dose do esquema vacinal e da imunoglobulina humana hiperimune, recomendado que seja feito na sala de parto ou até 12 horas após o parto. A transmissão do vírus da hepatite CVHC através do aleitamento materno não está comprovada, porém é recomendado o manejo adequado para prevenção de fissuras nas mamas (Zheng, 2011; Dibba, 2018).

Para evitar a transmissão vertical de doenças infecciosas como as hepatites B e C e garantir a amamentação de forma segura, a formação continuada dos profissionais de saúde, com valorização no acolhimento, no acompanhamento, na busca ativa de gestantes, o diagnóstico precoce e o tratamento oportuno são fundamentais, pois são vários os agentes interferentes sendo importante trabalhar estratégias para sensibilização e adesão dos profissionais de saúde (Huang, 2020; Brasil, 2021). 
O objetivo deste estudo foi analisar o conhecimento de profissionais da saúde sobre os protocolos para controle e prevenção das Hepatites B e C: da gravidez à amamentação.

\section{Metodologia}

Esta pesquisa tem abordagem qualitativa usando como aporte teórico Bardin (2011) que define análise de conteúdo como um método de categorias que permite a classificação dos componentes do significado da mensagem em espécie de gavetas. Segundo a autora, uma análise de conteúdo não deixa de ser uma análise de significados, ao contrário, ocupa-se de uma descrição objetiva, sistemática e quantitativa do conteúdo extraído das comunicações e sua respectiva interpretação.

A população de estudo foi profissionais de saúde no contexto do atendimento, na linha do cuidado da gravidez à amamentação, tendo como local de estudo a maternidade pública de referência no estado do Pará, em uma abordagem de multidisciplinaridade da compreensão e aplicação do conhecimento face à questão norteadora deste estudo. Qual o conhecimento dos profissionais da saúde sobre controle e prevenção das hepatites B e C na linha do cuidado da gravidez à amamentação?

A pesquisa foi realizada em fevereiro de 2019 e teve como população de estudo servidores da área da saúde, multidisciplinar, dos níveis médio e superior, bem como residentes dos programas de residência em saúde da referida maternidade, sendo esperado uma população de no mínimo 10 e máximo 20 participantes. Foram incluídos profissionais e residentes pertencentes a escala de serviço da instituição e das áreas do ambulatório de grávidas, maternidade, banco de leite e sala de parto, que aceitarem participar da pesquisa. Inicialmente foi feita sensibilização interna sobre a necessidade de participação de profissionais e residentes dos cenários descritos na pesquisa. Os interessados receberam o TCLE e após concordância, assinaram o mesmo e tiveram acesso ao link para preenchimento do questionário.

Para obtenção dos dados foi utilizado um formulário eletrônico, com quatro questões relacionadas à percepção e uso dos protocolos para controle e prevenção das hepatites B e C da gravidez à amamentação no hospital de referência. Quais sejam: 1. Quais os cuidados no pré-natal para prevenção e controle da Hepatite B e C? 2. Quais os cuidados na sala de parto para prevenção e controle da Hepatite B e C? 3. Quais os cuidados para prevenção e controle da Hepatite B e C na amamentação? 4. O que a você sugere que a maternidade faça para os cuidados materno-infantil na prevenção e controle das Hepatites $\mathrm{B}$ e C da gravidez à amamentação?

Para a organização e análise dos dados foi utilizado o software Interface de R pour les Analyses Multidimensionnelles de Textes et de Questionnaires (IRAMUTEQ), programa que permite a análise de textos e a organização com representações gráficas a partir de análises lexicográficas. Isto é, permitiu realizar análises simples, como a lexicografia básica, lematização e cálculo de frequência de palavras; até análises multivariadas como classificação hierárquica descendente (CHD), análise pósfatorial de correspondências e análises de similitude ${ }^{14,15}$.

Cada entrevista, composta por conteúdos semânticos, formaram o banco de dados ou corpus analisado pelo software. A estruturação dos dados foi feita com base em categorias semânticas, que emergiram a partir do processamento de dados, por meio da Nuvem de Palavras, que agrupou as palavras e as organizou graficamente em função da sua frequência no texto; Grafo de Similitude, que possibilitou identificar as ocorrências entre as palavras, bem como as partes comuns e as especificidades apontadas pela descrição e análise das variáveis identificadas ${ }^{14}$.

O projeto foi submetido para apreciação ética dando entrada pela instituição Proponente (UEPA) e com a carta de aceite institucional das coparticipantes: SESPA, IEC e Maternidade Púbica, sendo autorizado sob o parecer número: 2.037.289. 


\section{Resultados}

Participaram da pesquisa 23 profissionais de saúde que responderam ao questionário eletrônico. No entanto, foram excluídos 3 questionários que não estavam completamente respondidos, restando 20 questionários a serem analisados.

O perfil dos participantes quanto ao vínculo institucional foi de 52,2\% residentes, 39,1\% servidores do nível superior e $8,7 \%$ servidores dos níveis médio e elementar (Figura 1).

Figura 1 - Participantes do estudo sobre "Percepções do cuidado para prevenção e controle das hepatites B e C da gravidez à amamentação", Maternidade de Referência em Gravidez de Alto risco, Belém-PA,

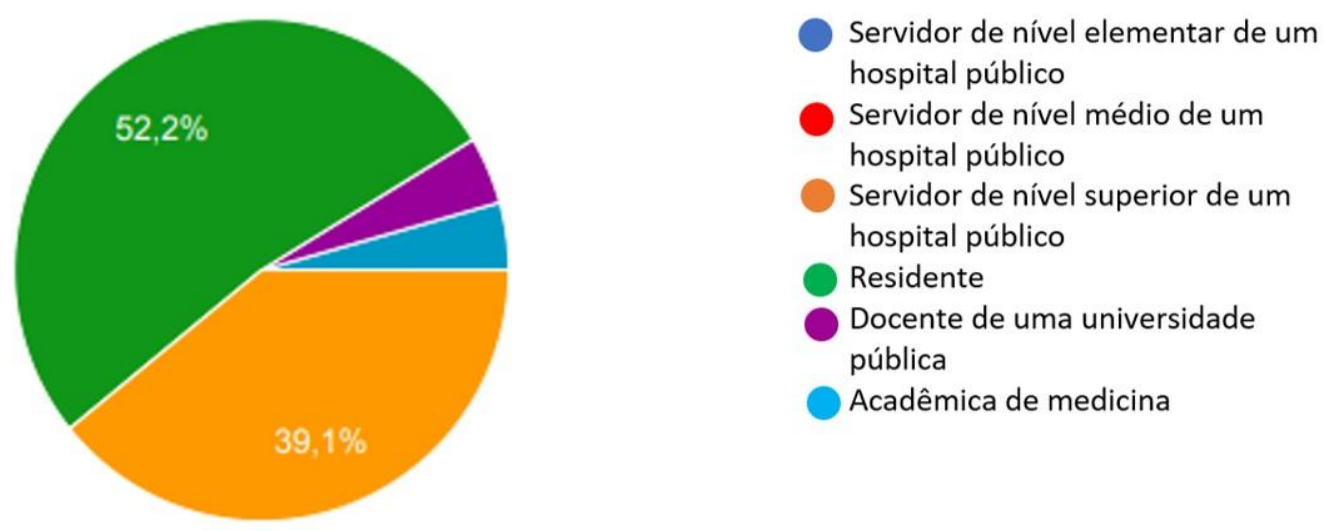

Fonte: Protocolo da pesquisa.

As respostas foram organizadas em um corpus textual e aplicadas ao software IRAMUTEQ. Posteriormente foi feito exploração do material buscando as unidades de registro, agregando as informações como forma de chegar as categorias à interpretação e análise à luz dos protocolos.

A aplicação do método levou à formação de uma unidade de organização e suas categorias, a saber:

A Unidade Prevenção e Controle das Hepatites B e C, subdividida em categorias, segundo os protocolos preconizados para o pré-natal, sala de parto e amamentação, seguindo a linha do cuidado materno-infantil, sendo organizada a frequência das respostas de cada participante.

A primeira categoria- Procedimentos no pré-natal: “Quais os cuidados no pré-natal para prevenção e controle da Hepatite B e C?

Obteve-se seis (6) respostas citando os testes rápidos para hepatite B e C como conduta neste período; cinco (5) respostas citaram a vacina para hepatite B como cuidado e três (3) participantes citaram a necessidade de encaminhar a grávida com diagnóstico de hepatite para o pré-natal de alto risco, conforme pode ser verificado nas falas:

“Conheço pouco, sei que existe, mas não sei como funciona” (P07).

“Não aplico porque não cabe a minha área de atuação” (P19).

“Não vejo divulgação e não vi a utilização ainda, não conheço nenhum protocolo" (P20).

A segunda categoria- Sala de parto: "Quais os cuidados na sala de parto para prevenção e controle da Hepatite B e C?"

Dezoito (18) respostas citaram a imunização com imunoglobulina B como procedimento obrigatório para filhos de mães portadoras de hepatite B e 20 que citaram a imunização do Recém-nascido (RN) para hepatite B como procedimento obrigatório. 
Os participantes P02; P05; P14 e P18 falaram que "paciente que é portadora do vírus B ou C, são encaminhadas para acompanhamento no ambulatório do grupo do fígado e pré-natal de alto-risco".

Entre os participantes P01 à P20, com exceção do P07, P19 e P20, "aplicação da Imunoglobulina B na sala de parto" foi citado como procedimento necessário para filhos de portadora do vírus da hepatite $\mathrm{B}$.

Os participantes P01 à P20, todos citaram que "deve ser realizado a vacinação para o recém-nascido":

"Conheço pouco, sei que existe, mas não sei como funciona (P07).

"Não aplico porque não cabe a minha área de atuação" (P19).

"Não vejo divulgação e não vi a utilização ainda, não conheço nenhum protocolo" (P20).

A terceira categoria - Amamentação, usando a pergunta: "Quais os cuidados para prevenção e controle da Hepatite B e C na amamentação?"

Quanto à possibilidade de amamentação para portadoras de Hepatites virais, 16 participantes responderam poder amamentar, 3 responderam não poder, 3 responderam não saber. Ainda nesta questão, 7 citaram que as mães precisam ser orientadas sobre a amamentação, dos quais 3 destacaram a ausência de fissuras como fator condicionante para a recomendação e prescrição da amamentação.

"HBV os filhos devem ter recebido a vacina e a imunoglobulina antes da amamentação e em ambos os casos (HCV e $H B V)$ o tecido mamário deve estar integro sem fissuras" (P01).

"Sim pode amamentar, vacinar o $R N$ em caso de hepatite $B$, em caso de hepatite c não existe evidência de que a contraindicação da amamentação evite a transmissão" (P03; P12; P13; P18).

"Sim, desde não tenham fissuras ou sangramentos" (P02; P09; P10; P14; P15; P16; P17).

"Podem amamentar, uma vez que risco maior de transmissão se dá por contaminação com sangue na ocasião do parto podem, após vacina e imunoglobulina. Cuidar das mamas para evitar no período de lesões mamilares (P05; P06; P09).

"Não sei" (P04; P08; P11).

"Até onde sei, não é recomendado" (P07).

"Não amamentar e o procedimento seria a orientação para elas de como proceder" (P19).

"Não pode, pois, o vírus tem alto potencial de contaminação" (P20).

$\mathrm{Na}$ quarta categoria - Referente às sugestões, a questão "O que você sugere que a maternidade faça para os cuidados materno-infantil na prevenção e controle das Hepatites B e C da gravidez à amamentação?"

Obteve 8 respostas, que enfatizaram a educação em saúde e a educação permanente.

"Uma palestra anual para os residentes de GO e Pediatria para nivelar o nivel de conhecimento dos médicos e enfermeiros" (P03). "Campanhas de conscientização da equipe de saúde e comunidade Orientação as mães, encorajando amamentação e pré-natal adequado" (P07).

"Fazer orientações as grávidas (P09).

"Realização uma vez por mês de palestras para as mães sobre os cuidados contra Hepatite B e C" (P12).

"Divulgação, panfletagem, nas salas de espera e triagem" (P14).

"Não consigo opinar, mas acho que precisa de educação (P18). 
"Não vejo divulgação e não vi a utilização ainda (P19).

"Aumentar o conhecimento da população geral sobre a situação" (P20).

O processo de análise pela Nuvem de Palavras agrupa as palavras do corpus textual e as organiza de forma graficamente aleatória a partir das frequências. Isto é, quanto maior o tamanho da palavra, maior a sua representatividade no texto. Nesse sentido, na Figura 2, as palavras mais evocadas foram: Imunização $(N=31)$, Hepatite B $(N=29)$, e Protocolo $(N=27)$, respectivamente. Desta forma, considera-se que a Nuvem de Palavras faz um apanhado geral sobre os conteúdos das entrevistas.

Figura 2 - Nuvem de palavras sobre o conhecimento de profissionais de saúde e residentes dos cuidados para controle e prevenção de hepatites da gravidez à amamentação, Belém- Pará, 2019.

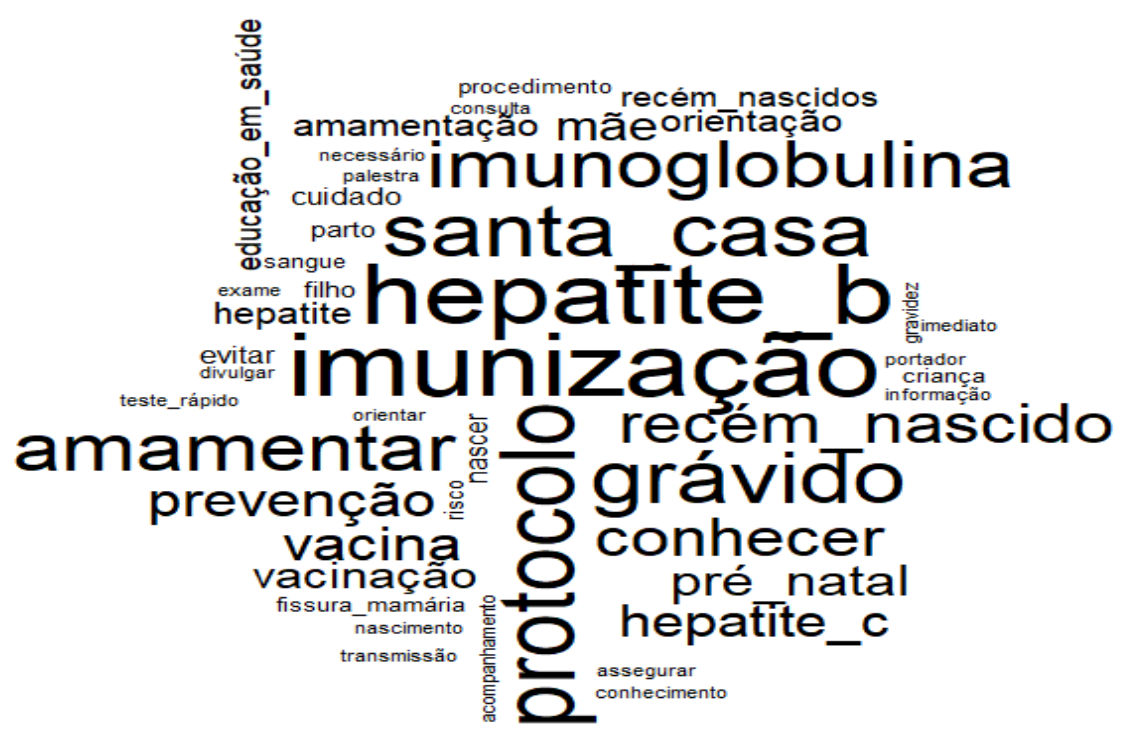

Fonte: Protocolo de pesquisa.

A partir da análise baseada na teoria dos grafos, é possível identificar as ocorrências entre as palavras e a indicação da conexidade entre elas, verificada por meio da espessura dos troncos que as ligam, o que auxilia na identificação do conteúdo de um corpus textual (Figura 3). 
Figura 3 - Análise da Similitude das respostas de profissionais de saúde e residentes quanto aos conhecimentos sobre os protocolos para controle e prevenção de hepatites B e C da gravidez à amamentação, Belém- Pará, 2019.

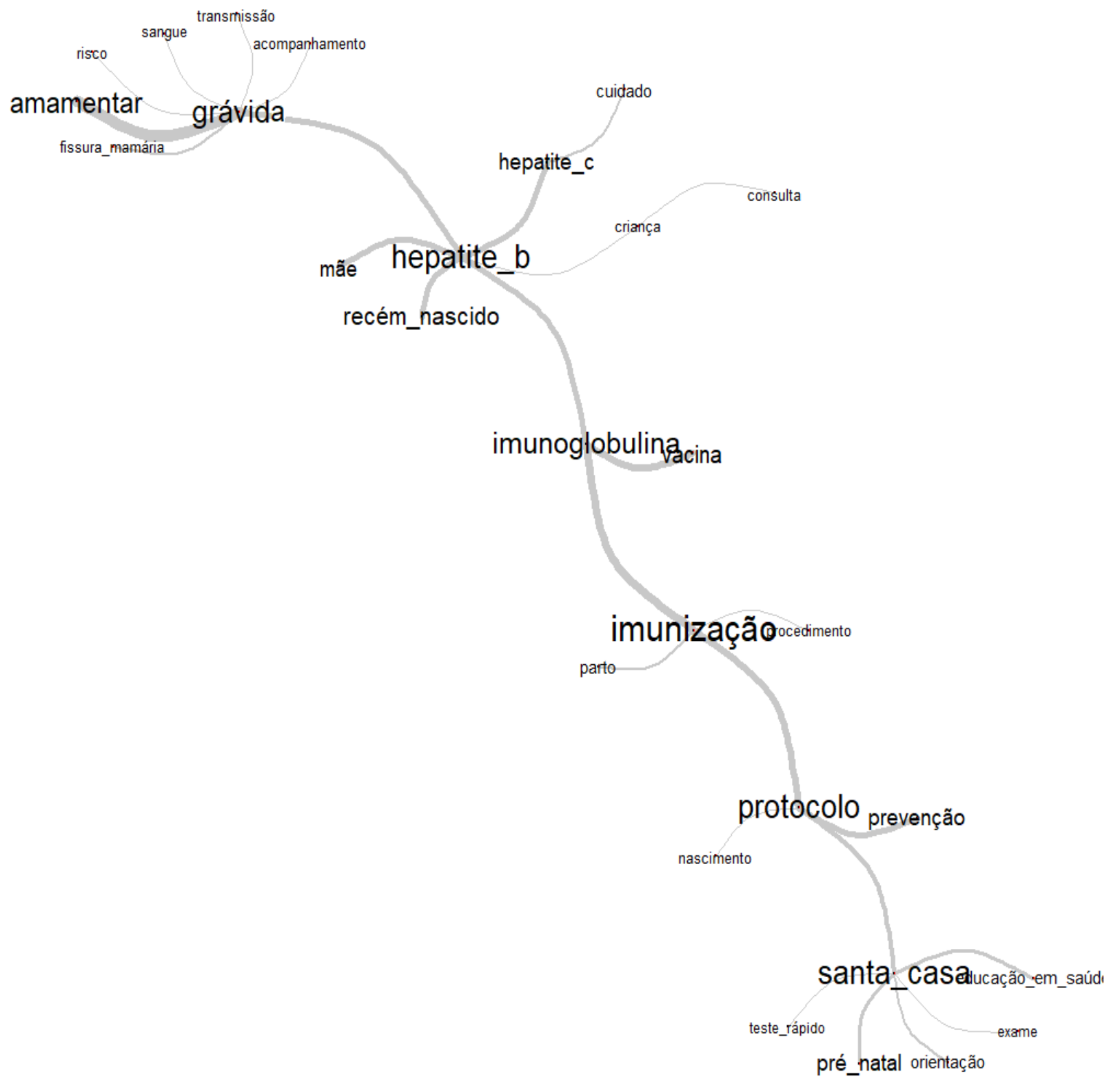

Fonte: Protocolo de pesquisa.

\section{Discussão}

Analisando os resultados observa-se que, na abordagem referente ao conhecimento, as palavras "conheço pouco", "não sei como funciona", "não conheço", sugerem um certo desconhecimento aos protocolos de teste rápido para hepatite B e C e imunização para hepatite B previstos para o pré-natal (Borgia, 2012; Brasil, 2015; 2021).

As respostas referentes à questão 2 são importantes considerando o número de 20 profissionais consultados na maternidade de referência do estado e as oportunidades de melhorias que precisam ser resolvidas no sentido de conhecer e 
aplicar as recomendações para portadores de hepatite B e C na sala de parto (Borgia, 2012; Brasil, 2015; Geraldo Duarte, 2021).

Em relação à amamentação, foi importante identificar que, apesar dos procedimentos previstos nos protocolos de prevenção e controle, o uso destes na linha do cuidado ainda tem lacunas, talvez por isso tenha surgido elementos na fala de "não saber" por 8 participantes, que mais à frente apresentaram sugestões à questão 4 "O que a você sugere que a maternidade faça para os cuidados materno-infantil na prevenção e controle das hepatites B e C da gravidez à amamentação?", sugerindo a promoção de ações de educação em saúde à comunidade e Educação Permanente aos Profissionais de Saúde.

Visando uma percepção gráfica das respostas, foi usado o software IRAMUTEQ, que trouxe as seguintes formas de expressão: na nuvem de palavras (Figura 2), surgiram com maior frequência as palavras: "imunização"; "hepatite B"; "protocolo"; "imunoglobulina"; "amamentar"; "prevenção"; "conhecer" e "vacina". Esta análise evidenciou que os profissionais de saúde trazem em seus discursos a ideia dos procedimentos de prevenção para controle das hepatites virais previstos nos protocolos da linha de cuidado materno-infantil ${ }^{9}$, mas também foi evidenciado nesta análise a palavra “conhecer”, sugerindo a necessidade de aprimoramento sobre este conteúdo. A análise de similitude possibilitou identificar as coocorrências entre as palavras indicando conexidade entre as mesmas, agregando expressões que surgiram no discurso dos pesquisados, ratificando as palavras "grávida"; "amamentar"; "hepatite B"; "imunoglobulina"; "vacina"; "imunização"; "protocolo", evidenciando o conhecimento dos procedimentos previstos no protocolo para prevenção e controle da transmissão vertical das hepatites Virais (Brasil, 2015;2021).

Estudo de metanálise realizado por Nigel C Rollins (2015) identificou fatores contextuais nas tendências da amamentação [...] "as sinergias criadas por meio de um conjunto de intervenções pode melhorar a amamentação, como treinamento dos trabalhadores da saúde e ao mesmo" [...]. A liderança e o investimento do governo, juntamente com a participação ativa da sociedade civil sustentam os avanços da amamentação no Brasil, não obstante, o País é o décimo maior mercado para fórmulas infantis e a projeção é de que atingisse 951 milhões de dólares em 2019. Neste contexto, é considerado como fragilidade no processo a disponibilidade de acesso ao uso de fórmulas infantis, principalmente em hospitais no período perinatal, sem justificativa baseada em evidências científicas. Portanto, estratégias de implantação, implementação e divulgação dos procedimentos de controle e prevenção da transmissão vertical de hepatite $\mathrm{B}$ ou C é o caminho que gestores devem buscar.

As hepatites não são contraindicadas ao aleitamento materno e mães infectadas com VHC ou VHB devem ser encorajadas a amamentar, pois contém baixa carga. O risco é um sangue infectado, porém um manejo de posicionamento e pega adequada da mama previne esse risco com a prevenção de problemas de mamas. Para tanto, a equipe multiprofissional necessita ter evidências científicas bem compreendidas e um treinamento para aleitamento materno, o que não deva ser dificuldade num hospital referência em saúde materna-infantil e centro de referência em doenças hepáticas (Post JJ, 2017; Brasil, 2016).

Para Cottrell et al. (2013) “...A decisão de amamentar ou não em mães VHC positivas deve ser baseada em uma discussão informada entre a mãe e o profissional de saúde...”. Pan Huang (2015) diz que “...o sucesso da amamentação depende da educação e de apoio prestado por profissionais de saúde", portanto a autonomia é um exercício de direito materno e dever dos profissionais da saúde.

Yakovchenko et al. (2019), em uma avaliação formativa utilizando entrevistas semiestruturadas com profissionais da saúde, identificou sugestões para práticas de teste e vinculação para os cuidados primários de VHC como intervenção multicomponente em torno da conscientização e educação, feedback de dados de desempenho, atualizações de lembretes clínicos e suporte à liderança, seriam abordagens significativas sendo consideradas aceitáveis e viáveis para os prestadores de cuidados. 
As novas possibilidades de sociabilização das informações em saúde proporcionadas pelas novas tecnologias, fenômeno denominado Cibercultura, permite construir atividades coletivas relacionadas ao cuidado e à educação em saúde, sendo um caminho que aumenta a possibilidade de sucesso no controle e prevenção de agravos. Moretti et al. (2012) demonstrou que para $86 \%$ dos entrevistados, a internet é a principal fonte de informação sobre saúde, corroborando com os estudos de Honorato 2014) sobre a interligação entre saúde e Cibercultura, trazendo o seu potencial para divulgação e disseminação de informações.

Portanto, novas formas de atualização profissional continuada, de baixo custo como as redes sociais, possibilitam que a equipe multiprofissional de saúde esteja mais bem preparada para realizar o apoio adequado no manejo da amamentação, com ação sustentável para a família e rede de assistência à saúde, evitando custos com a cadeia de produção de fórmulas lácteas e, além de minimizar os impactos ambientais.

\section{Conclusão}

Este estudo foi capaz de identificar que a linha de cuidados em maternidade para a prevenção da transmissão vertical precisa de estratégias de educação e saúde, educação permanente e continuada, na percepção de residentes e profissionais de saúde.

A disseminação das evidências científicas de que a amamentação de portadoras de HVB ou VHC não é fator de risco, necessitam de fortalecimento junto a profissionais, com o objetivo de que realizem os procedimentos de forma segura, tendo com amplo e contínuo esclarecimento sobre as dimensões do aleitamento materno, nutricional, afetiva, abrangendo aspectos sociais, com ênfase na economicidade e sustentabilidade deste processo.

Outro ponto fundamental para o estabelecimento da amamentação é a atitude de apoio útil em cada fase do pré-natal dos profissionais da saúde ao binômio mãe-bebê, principalmente no período perinatal, bem como o fortalecimento de uma rede de apoio para o segmento adequado ao aleitamento materno seguro na ocorrência de hepatites B e C.

Sugerimos novos estudos com a rede de atenção à saúde, população e tempo de coleta maiores, o que possibilitará um diagnóstico mais amplo, servindo de subsídio para tomada de decisão de gestores na perspectiva de eliminação da transmissão vertical.

\section{Referências}

Batista, C. B., \& Silva, L. R. Sentimentos de mulheres soropositivas para HIV diante da impossibilidade de amamentar. Esc. Anna Nery 11(2): 268-75. http://www.scielo.br/pdf/ean/v11n2/v11n2a13.pdf.

Bardin, L. Análise de conteúdo. Edições 70, 2011, 229 p.] Palavras-chave: Análise do conteúdo; Dados qualitativos; Análise de dados.

Brasil. Ministério da Saúde. Coberturas vacinais no Brasil Período: $2010 \quad$ MS http://portalarquivos2.saude.gov.br/images/pdf/2017/agosto/17/AACOBERTURAS-VACINAIS-NO-BRASIL---2010-2014.pdf.

Brasil. Protocolo Clínico e Diretrizes Terapêuticas para Prevenção da Transmissão Vertical de HIV, Sífilis e Hepatites virais. Ministério da Saúde. Secretaria de Vigilância em Saúde Departamento de DST, Aids e Hepatites Virais, 2015 http://www.aids.gov.br/pt-br/pub/2015/protocolo-clinico-e-diretrizesterapeuticas-para-prevencao-da-transmissao-vertical-de-hiv.

Brasil. Ministério da Saúde. Manual Técnico para o Diagnóstico das Hepatites Virais. Brasília: MS 2016. http://www.aids.gov.br/pt-br/pub/2015/manualtecnico-para-o-diagnostico-das-hepatites-virais.

Brasil. Ministério da Saúde. Secretaria de Vigilância em Saúde. Departamento de Vigilância das Doenças Transmissíveis. Fluxogramas para prevenção da Transmissão Vertical do HIV, Sífilis e Hepatites B e C nas instituições que realizam parto / Ministério da Saúde, Secretaria de Vigilância em Saúde, Departamento de Vigilância das Doenças Transmissíveis. - Brasília: Ministério da Saúde, 2021.

Borgia, G., Carleo, M. A., Gaeta, G. B., Gentile, I. Hepatitis B in pregnancy. World J. Gastroenterol. 2012 https://www.ncbi.nlm.nih.gov/pmc/articles/PMC3442205/.

Camargo BV, Justo AM. IRAMUTEQ: um software gratuito para análise de dados textuais. Temas psicol. 2013 http://pepsic.bvsalud.org/pdf/tp/v21n2/v21n2a16.pdf. 
Cottrell, E. B., Chou, R., Wasson, N., Rahman, B., Guise, J. M. Reducing risk for mother-to-infant transmission of hepatitis C virus: a systematic review for the U.S. Preventive Services Task Force. Ann Intern. Med. https://www.ncbi.nlm.nih.gov/pubmed/23437438.

Dibba P, Cholankeril R, Li AA, Patel M, Fayek M, Dibble C et al. Hepatitis C in Pregnancy. Diseases https://doi.org/10.3390/diseases6020031.

Geraldo Duarte e colaboradores. Protocolo Brasileiro para Infecções Sexualmente Transmissíveis 2020: hepatites virais. Epidemiol. Serv. Saude, Brasília, 30(Esp.1): e2020834, 2021

Huang P, Ren J, Liu Y, Luo B, Zhao X. Factors affecting breastfeeding adherence among Chinese mothers. A multicenter study. Medicine 2020 https://insights.ovid.com/crossref?an=00005792-201709220-00003.

Honorato, E. J. S. A. A interface entre saúde pública e cibercultura. Ciên. saúde colet. 2014 http://www.scielo.br/pdf/csc/v19n2/1413-8123-csc-19-0200481.pdf.

Lahlou S. Text mining methods: an answer to Chartier and Meunier. Papers on Social Representations. 2012 http://eprints.lse.ac.uk/46728/1/Text\%20mining\%20methods\%281sero\%29.pdf.

Miranda, M. M. S., Souza, L. M. G., Aguiar, R. A. L. P., Correa, Jr M. D., Maia, M. M. M., Borges, R. S. et al. Rastreamento das infecções perinatais na gravidez: realizar ou não? Femina 2012 http://files.bvs.br/upload/S/0100-7254/2012/v40n1/a3075.pdf.

Moretti, F. A., Oliveira, V. E., Silva, E. M. K. Acesso a informações de saúde na internet: Uma questão de saúde pública? Rev. Assoc. Med. Bras. 2012 http://www.scielo.br/scielo.php?script=sci_arttext\&pid=S0104-42302012000600008.

Pais, I. P., Lourenço, C., Costa, C., Carrilho, M., João, A. Transmissão vertical do vírus da hepatite C: experiência clínica de um hospital de nível III. Acta Pediatr. Port. 2012 https://revistas.rcaap.pt/app/article/view/1280.

Piazza, M. J., Urbanetz, A. A., Carvalho, N. S., Nascimento, D. J. Hepatites virais e gestação. Diagn. Tratamento 2010 http:/files.bvs.br/upload/S/14139979/2010/v15n1/RDTv15n1a1054.pdf.

Post, J. J. Update on hepatitis C and implications for pregnancy. Obstet. Med. 2017 https://www.ncbi.nlm.nih.gov/pubmed/29225673.

Rollins, N. C., Lutter, C. K., Bhandari, N., Hajeebhoy, N., Horton, S., Martines, J. C. et al. Por que investir e o que será necessário para melhorar as práticas de amamentação? Epidemiol. Serv. Saúde http://scielo.iec.gov.br/pdf/ess/v25n1/Amamentacao2.pdf.

Tovo, P. A., Calitri, C., Scolfaro, C., Gabiano, C., Garazzino, S. Vertically acquired hepatitis C virus infection: Correlates of transmission and disease progression. World J. Gastroenterol. 2016 https://www.ncbi.nlm.nih.gov/pmc/articles/PMC4721973/.

World Health Organization. Global Hepatitis Report, 2017. WHO http://apps.who.int/iris/bitstream/handle/10665/255016/9789241565455eng.pdf?sequence $=1$

Yakovchenko, V., Bolton, R. E., Drainoni, M. L., Gifford, A. Primary care provider perceptions and experiences of implementing hepatitis C virus birth cohort testing: a qualitative formative evaluation. BMC Health Serv. Res. https://bmchealthservres.biomedcentral.com/articles/10.1186/s12913-019-4043-z.

Yogeswaran, K., Fung, S. K. Chronic hepatitis B in pregnancy: unique challenges and opportunities. Korean J. Hepatol. 2011 https://www.ncbi.nlm.nih.gov/pmc/articles/PMC3304622/.

Zhang, L., Gui, X., Wang, B., Ji, H., Yisilafu, R., Li, F., et al. A study of immunoprophylaxis failure and risk factors of hepatitis B virus mother-to-infant transmission. Eur. J. Pediatr. https://link.springer.com/article/10.1007/s00431-014-2305-7.

Zheng, Y., Lu, Y., Ye, Q., Xia, Y., Zhou, Y., Yao, Q., et al. Should chronic hepatitis B mothers breastfeed? a meta-analysis. BMC Public Health [internet]. 2011 https://bmcpublichealth.biomedcentral.com/articles/10.1186/1471-2458-11-502. 